\title{
H istórias de leituras: produzindo sentidos sobre Ciência e Tecnologia
}

\author{
Suzani Cassiani*, Irlan von Linsingen*, Patricia M ontanari Giraldi**
}

Resumo: A preocupação com o funcionamento da linguagem na educação científica e tecnológica tem-nos levado a percorrer caminhosqueprocuram desfazer ailusão datransparência da linguagem. Trazemos uma reflexão sobre as atividades desen volvidas no âmbito de uma disciplinana qual privilegiamos discussões sobrea noção de discurso eaprofundamentosacerca dossentidos construídossobreasrelações entreciência, tecnologiaesociedade(CTS). Entendemos que esses discursos não apenas comunicam sobretais conteúdos, mas que aquilo quesefalae como sefala da/sobreciênciaetecnologia produz efeitos desentidos. Além disso, compreendemos que aquilo que não é dito também contribui para a produção de sentidos. D essa forma, enfatizamoso trabal ho com as histórias deleituras deestudantes como umaforma pertinente de abordar a heterogeneidade de formações discursivas, estas pautadas em experiências, conhecimentose expectativas, construídosao longo desuas vidas, culminando em diferentes entendimentos sobreciênciaetecnologia.

Palavras-chave: educação em ciênciae tecnologia; formação deprofessores; leitura.

Readings stories: building up meaning on Science and Technology

Abstract: The concern with thefunctioning of languagein science and technology education has led us to ways that question theillusion of languagetransparency. In this work we present a reflection on theactivities developed within adisciplinein which weprioritizediscussionson the concept of discourse and on meanings about Science, Technology and Society (ST S) relations. Weunderstand that thesediscourses do not only communicate about such content, but also what and how is spoken about scienceand technology produces effects of meaning. M oreover, weunderstand that what isnot said also contributesto meaning build up. In this

* Professora do Departamento de Meto dologia de Ensino do Centro de Educação e do Programa de Pós-Graduação em Educação C ientífica e Tecnológica (PPGECT) e C oordenadora do Grupo de Estudos e Pesquisas D iscursos da C iência e da Tecno logia na Educação (D icite) da U niversidade Federal de Santa C atarina (UFSC), Brasil. suzanicassiani@ gmail.com

** Professor doutor do Departamento de Mecânica da UFSC e do Programa de Pós-Graduação em Educação Científica e Tecnológica (PPG ECT) e Pesquisador do Grupo de Estudos e Pesquisas D iscursos da C iência e da Tecno logia na Educação (D icite) da UFSC, Brasil. irlan.von@ gmail.com

*** Professora doutora do Centro de Educação a Distância da Universidade do Estado de Santa Catarina. Pesquisadora do G rupo de estudos e pesquisas $D$ iscursos da C iência e da Tecno logia na Educação (D icite) da UFSC, Brasil. patriciamgiraldi@ gmail.com 
regard, we emphasize the work with the stories of students' readings as an adequate way to understand theheterogeneity of discursiveformations based on experiences, knowledgeand experients build along their lives, , culminating in different understandings about scienceand technology.

Key w ords: scienceand technology education; teacher education reading.

\section{Considerando a linguagem}

... há quem leve a vida inteira a ler sem nunca ter conseguido ir mais além da leitura, ficam pegados à página, não percebem que as palavras são apenas pedras postas a atravessar a corrente de um rio, se estão ali é para que possamos chegar à outra margem, a outra margem é

que importa.

José Saramago, A caverna

A preocupação com questões de linguagem tem-nos levado a procurar caminhos (de pesquisa e de ensino) que permitam abordá-la de forma menos naturalizada. Tendo isso em vista, em nosso trabalho buscamos refletir acerca da linguagem em uma perspectiva que a considere não como instrumento de comunicação, mas, sim, como parte integrante da própria construção de compreensões acerca dos contextos histórico-sociais. Assim, visamos desenvolver trabalhos que problematizem a linguagem enquanto prática social ${ }^{1}$. Além disso, por meio dessa abordagem podemos tecer outras formas de entendimento sobre práticas culturais que interessam à educação, como é 0 caso das relações entre ciência e tecnologia e suas implicações sociais.

D e acordo com os referenciais adotados, trabalhamos na perspectiva de que a linguagem permeia toda e qualquer forma de conhecer, seja ela escrita, oral, gestual ou imagética. N esse quadro teórico que estamos traçando, um conceito que se torna importante é o de discurso, entendido como "palavra em movimento" ou, como afirma Pêcheux, efeito de sentidos entre interlocutores. 0 discurso, ou esse efeito de sentidos, é produzido na interação (discursiva) entre sujeitos que, ao falar/ouvir, situam-se em determinadas posições, inscritos em formações discursivas. É a partir dessas posições discursivas que os sujeitos irão produzir sentidos. Portanto, podemos compreender que, de acordo com a formação discursiva em que os sujeitos se inserem, existe a produção de alguns sentidos dominantes.

1. Essas preocupações envolvendo a linguagem e seu funcionamento tornaram-se, ao longo dos últimos cinco anos, o foco central do grupo de estudos e pesquisas "D iscursos da Ciência e da Tecnologia na Educação" (DIC ITE). 0 grupo desenvolve seus trabalhos junto ao Programa de Pós-Graduação em Educação Científica e Tecnologia (PPGECT) da Universidade Federal de Santa C atarina. 
N o presente trabalho, fazemos uma reflexão sobre as atividades desenvolvidas no âmbito de uma disciplina² cujo público-alvo tem sido professores em serviço, provenientes das áreas das ciências e tecnologia. N essa disciplina, os estudantes são desafiados a refletir sobre as questões da não transparência da linguagem, aprofundando os aspectos relacionados ao funcionamento dos discursos na educação, focando, principalmente, as relações entre Ciência, Tecnologia e Sociedade (CTS). Temos como mote, nestas discussões, os discursos referentes a ciência e tecnologia, compreendendo-os como locais de construção e circulação de sentidos. 0 u seja, entendemos que esses discursos não apenas comunicam ou informam sobre tais conteúdos, mas o que se fala e como se fala sobre ciência e tecnologia produz efeitos nos leitores, constituindo compreensões, e isso se dá em condições determinadas sócio-historicamente.

Q ual a contribuição desses olhares sobre o funcionamento da linguagem na educação, para repensar a formação de educadores? Q ue relação entre linguagem e educação pode ser estabelecida para promover transformações relevantes na educação em ciência e tecnologia?

\section{Educação científica e tecnológica numa perspectiva discursiva: contribuições dos estudos de CTS}

O s estudos de Ciência, Tecnologia e Sociedade (ECTS) constituem um campo de trabalho de caráter crítico com relação à tradicional imagem essencialista da ciência e da tecnologia, e de caráter interdisciplinar, para o qual concorrem disciplinas como a filosofia da ciência e da tecnologia, a sociologia da ciência e da tecnologia, a teoria da educação e a economia da mudança tecnológica.

Basicamente, partimos da crítica à concepção linear que enxergava a ciência como processo de desocultamento dos aspectos essenciais da realidade, de desvelamento de leis que a governam em cada parte do mundo natural e social. N essa concepção, tanto ciência quanto tecnologia e, por extensão, todas as áreas técnicas que Ihes dão sustentação, deveriam estar al heias a interesses, opiniões e valorações.

A caracterização do novo enfoque das relações entre ciência, tecnologia e sociedade é fundamentalmente contrária à imagem tradicional da CT - assumida como atividade autônoma que se orienta exclusivamente por uma lógica interna e livre de valorações externas. Transfere o centro de responsabilidade da

2. A disciplina Seminários de Linguagem: $D$ iscursos da C iência e Tecnologia na Educação faz parte do quadro de disciplinas optativas do programa de pós-graduação em Educação Científica e Tecno ló gica da U FSC (PPGECT-UFSC), é ministrada pelos dois primeiros auto res deste trabalho e vem sendo oferecida desde 2005. 
mudança científico-tecnológica para os fatores sociais, ou seja, o fenômeno científico-tecnológico passa a ser entendido como inerentemente social, e seus elementos não epistêmicos ou técnicos, como valores morais, convicções religiosas, interesses profissionais, pressões econômicas, etc. desempenham um papel decisivo na gênese e na consolidação das ideias científicas e dos artefatos tecnológicos.

A pesar de os ECTS assumirem essa posição de rechaço à percepção tradicional da ciência e tecnologia, vemos a necessidade de aprofundar aquilo que temos percebido como polissemia de CTS, já que vários sentidos sobre essas relações vêm sendo construídos a partir de diferentes campos de saber, posições de sujeito e suas filiações a sentidos. De que Ciência e Tecnologia estamos falando, quando o que está em pauta é a percepção de benefício social numa perspectiva hegemônica? E por que CTS? Porque CTS traz uma nova maneira de olhar para o que está cristalizado, para os sentidos historicamente construídos e naturalizados. Se ciência e tecnologia não são neutras e são conformadas por valores e interesses conflitantes, que transformações a desnaturalização que esse novo olhar provoca sobre CT poderá acarretar ao ensino tecnocientífico?

Assim, educar numa perspectiva CTS é, fundamentalmente, possibilitar uma formação para maior inserção social das pessoas no sentido de tornarem-se aptas a participar dos processos de tomadas de decisões conscientes e negociadas em assuntos que envolvam ciência e tecnologia (Linsingen, 2007, p. 13).

Essa percepção educacional CTS possui implicações que vão muito além da inserção social para um consumo consciente e converge significativamente para aspectos proposicionais de democracia radical, como proposto por Ernesto Laclau eC hantall M ouffe, e de democracia participativa, como percebida por Boaventura de Sousa Santos 3 . A perspectiva educacional CTS que adotamos aqui pode ser compreendida como inserida no âmbito do que se tem denominado de perspectiva CTS crítica (D agnino, 2008), que entendemos aproximar-se da perspectiva educacional crítica no sentido freireano ( $N$ ascimento; Linsingen, 2006).

$\mathrm{N}$ ão é uma abordagem que se possa fazer com facilidade no ensino de ciências, principalmente se pensarmos na multiplicidade e na complexidade que envolvem a educação escolar, 0 ato de ensinar e todos os demais aspectos que não têm sido contemplados pelo enfoque CTS. Afinal, o que estamos fazendo é buscar aproximar o ensino de ciências e tecnologia dessa percepção de com-

3. 0 assunto é tratado por Marques (2008, p. 1). Para a autora, as concepções hegemônicas de democracia tratam da participação demo crática "como forma de legitimação de uma integração consentida", à qual se contrapõem "teorias democráticas que se colocam no campo das teorias não hegemônicas, nas quais a participação é um elemento de emancipação e, portanto, de mudança social". 
plexidade contextual que se abriu com a assunção da não neutralidade e da não essencialidade da ciência e da tecnologia, a partir dos ECTS.

Assim é que pensamos CTS numa perspectiva discursiva. As novas percepções das relações CTS, a partir das quais os sentidos hegemônicos conferidos ao ensino de ciências e tecnologia se transfiguram pela desnaturalização favorecida pela problematização e pela dialogicidade, abrem portas para a construção de novos sentidos sobre a ciência e a tecnologia e, implicadamente, para novas percepções de sociedade e dos papéis dos atores sociais.

\section{Histórias de leituras: movimento de sentidos so bre ciência e tecnologia na educação}

Entre tantas questões abordadas na disciplina, neste artigo enfatizamos as histórias de leituras dos estudantes, como forma de problematizar discursos (e sentidos) sobre as relações entre ciência, tecnologia e sociedade. Assim, este trabalho apresenta algumas análises centradas num material escrito solicitado aos estudantes. É uma escrita mais autoral, em que estes são estimulados a resgatar as próprias histórias de leituras e, ao mesmo tempo, trazer à discussão suas práticas de leitura. Acreditamos que o trabalho com esse tipo de escrita contribua para a própria formação desses estudantes, uma vez que possibilita a tomada da palavra como forma de reflexão e a compreensão de al guns processos de produção de sentidos vinculados às diferentes leituras empreendidas em diferentes momentos de suas histórias. Além disso, a redação de um tema que leva em conta questões pessoais pode ser rara na universidade, ainda mais em áreas consideradas "técnicas", como é o caso das engenharias e das ciências naturais (C assiani de Souza; N ascimento, 2006). Q uando se trata de conhecimento científico, esse distanciamento de questões de linguagem pode trazer diversas consequências indesejáveis para a aprendizagem. Uma delas está em perceber a ciência como conhecimento inquestionável, infalível, pronto, que tem como resultado o desenvolvimento de visões de ciência neutra, objetiva, que retrata fielmente a realidade e independe das relações sociais estabelecidas.

Se retomarmos aqui a noção de discurso como efeito de sentidos entre interlocutores, podemos inferir que, ao produzir leituras ${ }^{4}$, estamos entrando no jogo de produção de sentidos. É nesse jogo que haverá a constituição histórica dos sujeitos. Podemos dizer que os sujeitos (leitores) se constituem, assim, na/pela linguagem. O rlandi (1996) aponta que, ao longo dos processos de

4. Entendidas aqui não no sentido estrito, de leitura de palavras escritas em forma de um texto, mas de forma mais ampla, considerando-a como um gesto de interpretação, ou seja, por meio da leitura de diferentes textos produzimos sentidos so bre a realidade sócio-histórica. 
escolarização, os estudantes são levados a reproduzir leituras esperadas sobre um texto, em um processo que busca responder às questões de leitura e de escrita, de modo a contemplar os sentidos e as formas de dizer institucionalmente aceitos pela escola, o que a autora chama de mecanismo de antecipação. Entendemos que a escrita deve ser um espaço de diálogo, um espaço aberto para ouvir o outro; deve possibilitar o dizer, porém não só do que é instituído.

\section{H istórias so bre as leituras}

N este primeiro enfoque, apontamos algumas relações das leituras dos estudantes com os espaços onde elas se deram. Em praticamente todos os relatos recebidos, temos a indicação do espaço escolar de forma marcante, algumas vezes de forma positiva e em outras de modo limitador. M uitos trabalhos (C assiani de Souza; Almeida, 2001; Cassiani de Souza; N ascimento, 2006; Souza; Bohn, 2003;), têm enfatizado que inúmeras vezes, ao longo do processo de escolarização, há o apagamento da voz dos estudantes. Isso foi identificado em nossas análises em diversos relatos, como, por exemplo:

A primeira lembrança relacionada à leitura quemevem à memória éum testedeleitura quetinha na escola ondeestude nasséries iniciais. [... ] 0 testeera feito no horário da aula, masfora desala em um corredor próximo. Quem aplicava não era a professora (Ju).

N esse trecho, destacamos os possíveis desdobramentos da forma como a leitura é comumente trabal hada nas escolas. 0 fato de criar um espaço diferenciado para a cobrança da leitura dá indícios de como esta era vista pela escola: mera repetição de sentidos previstos para o texto. Esse tipo de postura certamente direciona a leitura dos estudantes, pois estabelece aquela considerada como "mais correta". Por outro lado, em outro relato é possível perceber a fruição, o gosto pela leitura, aliado às dificuldades de acesso aos textos:

Q uando batia o sinal do recreio, eu corria para a biblioteca elia sofregamentedurantequinzeminutos. Q uando tornava a bater 0 snal, a professora quecuidava da biblioteca meexpulsava. [... ] 0 maior presentequerecebi por ter sido aprovado na Escola T écnica foi a biblioteca ( $\mathrm{Pa})$.

Essa afirmação remete-nos às possibilidades de um trabalho diferenciado que poderia ser feito nas salas de aula, em que o gosto pela leitura não pode estar atrelado somente à obrigatoriedade. Também pudemos identificar algumas concepções de leitura diferenciadas e categorizamos basicamente duas: a primeira voltada à questão da leitura de textos em si, em que os autores destacam a importância da leitura como forma de apropriação de bens culturais por 
parte do leitor; e a segunda visão, mais abrangente, que aponta para a leitura como uma forma de entender o mundo, como destacamos nos trechos a seguir:

[... ] mesmo quemuitosjá tenham féto, julgo pertinentereafirmar que 0 ato da leitura permite 0 acesso amplo e extenso aos bens culturaisda humanidade(Fr).

[... ] nosreconhecemoscomo sereshumanosna medida em queentramosinterativamenteno universo sócio-histórico semiótico. D es sa forma, émaisapropriado falar em leitura demundo (Su).

Essa segunda perspectiva aproxima-se muito do que Paulo Freire defende em suas teses. Para ele, a tomada da palavra relaciona-se com as formas de ver 0 mundo. A leitura, assim, vai muito além da leitura das palavras. É uma leitura de contextos, que promove uma visão mais crítica sobre o mundo que nos rodeia. $\mathrm{N}$ as palavras de Freire:

Cadanovaleitura podeprovocar a descoberta, numa "esquina" mal iluminada do texto, de uma dimensão atéentão despercebida. É como se, uma vez escrito, o texto jamais deixasse de poder ser reescrito pelas leituras del e feitas por seus leitores. (Freireapud Freire, 2006, p. 404).

Assim, podemos dizer que um texto é sempre incompleto, pois seus sentidos não derivam das palavras ou das expressões em si, mas são constituídos com base na intertextualidade e no interdiscurso, na sua relação com a exterioridade. Podemos perceber esses fenômenos linguísticos na constituição de sentidos sobre leitura presentes nos relatos a seguir:

A tribuo quefoi a leitura dejohn D ewey, duranteo primeiro ano de graduação, quedeterminou boa partedasdemaisleituras Primeiro como referência para a prática pedagógica, depoiscomo motivação para leiturasopostas(An).

[... ] desenvolvo minhasatividadesprofissionais, enquanto profes sor, procurando me pautar no uso de livros, textos, artigos para desenvolver as atividades acadêmicas relativas à Educação Tecnológica (Fr).

Algunsfilmesforam muito significativospara queeu compreandesse melhor asleiturasdoslivros $\mathrm{H}$ oje quandoleio $\mathrm{M}$ anifesto Comunis ta, a cada leitura quefaço analiso por um ângulo diferente ( $\mathrm{C}$ a).

$\mathrm{N}$ esses excertos, evidenciamos as influências de diferentes tipos de leitura na constituição desses leitores como sujeitos profissionais da educação, ou seja, a presença da intertextualidade, diferentemente das análises feitas em outros trabalhos (C assiani de Souza; Almeida, 2001; Cassiani; N ascimento, 2006; 
Flor; C assiani, 2009), em que há apagamento dos textos que são a origem do nosso dizer. Esse fato remetenos às posições assumidas pelos sujeitos, nossos estudantes de pós-graduação (e mesmo às nossas, como pesquisadores), que ocupam um espaço social em que há necessidade de assumir referenciais teóricos. É de praxe, nesse nível de ensino, apontar a origem do seu dizer, em que há intenções variadas, incluindo a noção de colonização proposta por O rlandi (2003) e também de resistência.

D estacamos que, quando se trata de formação de educadores, essa reflexão mostra-se extremamente interessante, abrindo possibilidades de repensar o papel da escrita e da leitura em processos de escolarização.

\section{Ciência, Tecnologia e Sociedade: leituras possíveis}

Sabemos que a linguagem científica apresenta suas especificidades. Apesar da forma impessoal e da aparente ausência de um autor, a linguagem científica é produzida por um determinado autor, segundo suas representações, seus interesses e valores. Em textos científicos, por exemplo, é comum a presença de verbos em terceira pessoa do singular: "se deve", "se torna". Como entendemos que a forma e o conteúdo não se separam, defendemos a ideia de que essas formas de linguagem poderiam imprimir uma suposta neutralidade ao discurso científico, apagando-se o sujeito (Authier-Revuz, 1998). N esse caso, a linguagem científica é supostamente identificada como atributo de "verdade". Atkinson (1999) faz uma análise da Philosophical Transactions of Royal Society of London (PTRSL), entre 1675 e 1975, apontando como os sujeitos (homens e mulheres) vão se ausentando da autoria dos artigos científicos. Para Sutton (2003), ao omitir o papel central que a linguagem representa na construção de novos conhecimentos em âmbito científico, produz-se uma ideia incompleta e equivocada de ciências. Assim, compreender como a linguagem da ciência muda, à medida que seus conhecimentos são ampliados, pode ser uma solução possível para uma melhor compreensão de ciências como empreendimento humano.

$\mathrm{N}$ os relatos analisados, identificamos momentos em que os sujeitos se remetem à questão da linguagem científica: [... ] me deparei com leituras técnicas muito específicas que deveriam ser seguidas sem qualquer desvio. A cabei conhecendo nesse ínterim a famosa neutralidade dos artigos científicos (O r).

M esmo lembrando a posição que o estudante ocupa, a de um estudante de uma disciplina que questiona a neutralidade do discurso científico, e isso certamente pode influenciar a forma como ele diz, esse trecho mostra uma reflexão ausente em muitos acadêmicos universitários. Também é interessante notar que o estudante, ao utilizar a palavra "famosa" aponta, com certa ironia, a 
presença marcante de leituras que privilegiam a repetição, uma vez que há uma tentativa de fixar sentidos.

Se os sentidos são produzidos no processo de interação texto-leitor, e entendendo que cada leitor tem suas próprias histórias de leitura, que vão sendo retomadas na sua interação com 0 texto, naturalmente essas interpretações, mesmo sendo sobre um mesmo texto, podem ser diferenciadas. Consequentemente, podemos dizer, concordando mais uma vez com 0 rlandi (2006), que o sentido não existe em si, mas é determinado pelas posições ideológicas colocadas em jogo no processo sócio-histórico em que as palavras são produzidas. Voltando à questão da leitura em processos educativos, comumente vemos atividades voltadas à repetição mnemônica, em que os sujeitos não são estimulados a posicionar-se enquanto leitores produtores de sentidos sobre o que leem, apenas reproduzem as palavras do texto:

$N$ asváriasdisciplinas do mestrado, aprendi a ler artigoscientíficos eadquiri um pouco da ideia do fazer científico. D esenvolvi formas ecritérios deletitura dequefiz uso enosquaisacredite nosdez anos subsequentes: julgamento de coerência, objetividade científica, confiabilidadedosdadoseresultados... (Pa).

No trecho citado, percebemos que a afirmação do estudante denuncia e critica um processo de leitura que limita a condição do leitor. Com base nesses exemplos, podemos notar a forte presença da linguagem impessoal/científica por meio da qual é transmitida uma visão de ciência neutra e objetiva, em que observações sistematizadas e anotações cuidadosas têm papel central. Para Silva et al.,

o problema da transparência da linguagem talvez esteja relacionado aum certo imaginário positivista associado à necessidade quetemos de evidências. Como separa ser científico fossepreciso tratar nossos achados analíticos como se eles estivessem lá. ParaaAD a evidência dequeo sentido estáno texto, nafala, na imagem, éjá um efeito do funcionamento da linguagem. Funcionamento queéfundamental eessencialmentesócio-histórico eideológico. (Silva et al., 2006, p. 4)

D estacamos ainda que, em consonância com as discussões propostas na disciplina, os escritos de alguns estudantes levam em conta novas percepções das relações entre ciência, tecnologia e sociedade, que favorecem a construção de novos sentidos pelos interlocutores.

A partir mais ou menos da metade da universidade, comecei a participar deum grupo deestudantesorigináriosdedi ferentescursos(engenharias, economia, hisória, biologia... ) queintervinham 
na universidade, questionando seu papel social eas rel ações entre ciência, tecnologia esociedade. (Si)

Foi aí que, pela primeira vez, com a disciplina deCTS, queacabè desmontando o queeu vinha pregando, só quedemanerasdiferentes, a minha admi ração pela tecnologia. Como se tudo o que eu estivessefazendo era algo bom, ou seja, desenvolvo novastecnol ogias, logo isto ébom. Errado! D epois dequasetrinta anos das minhas primeirasleituras, tive a oportunidade de conhecer o outro lado. Tudo o que li já está ficando com outro sentido. $N$ ão me refiro somenteà leitura delivros, mastudo o queserefereaosśmbolosque eu vivo, como por exemplo: ojaleco branco queeu uso, a graduação utilizada para classificar osalunosda robótica... (O r)

$\mathrm{N}$ os trechos citados, evidenciamos a presença de questões CTS no contexto de formação dos autores dos relatos. Cabe dizer que o contato inicial dos estudantes com os enfoques CTS, entretanto, resulta da exposição a diferentes formações discursivas e filiações de sentidos presentes em diferentes disciplinas da pós-graduação naquele momento.

Diversos pesquisadores ressaltam a importância, para um processo de formação que se queira crítico, de trabalhos que abordem tais questões, cujo tratamento é fundamental para possibilitar a reflexão sobre as dimensões sociocultural e política dos conhecimentos científicos e tecnológicos, nos programas de formação de professores da área científico-tecnológica ou não, considerando o contexto em que vivemos.

\section{Considerações finais: a outra margem}

Tomando como inspiração as palavras de Saramago usadas na epígrafe deste trabalho, destacamos que todo o esforço de análise desenvolvido aqui esteve voltado à questão da leitura, que vai além da palavra. Como disse o autor, "é o que importa", uma vez que elas constroem o meio para a produção de entendimentos e visões de mundo. A pontamos algumas reflexões acerca do trabalho de análise realizado. Salientamos a importância de abordar questões de linguagem nos processos de formação profissional. Trazemos aqui um trecho de um dos relatos em que 0 autor aponta que: "[...] na escola os alunos deveriam ser incentivados a trabalhar com a polissemia, pois acredito que só através dela poderemos ter uma visão mais ampla e crítica do mundo". (O r)

Do ponto de vista dos objetivos do ensino escolar fundamental, médio, pós-médio e universitário, tal afirmação pode parecer um tanto quanto controversa, indesejável ou "descolada". No entanto, acreditamos que lançar outros olhares sobre velhas questões permite vislumbrar possíveis caminhos para um ensino que não beire a repetição que apenas prioriza a memorização de concei- 
tos "neutros", mas, sim, que promova a construção de conhecimentos nos processos de ensino-aprendizagem. A perspectiva aqui considerada é, evidentemente, a de uma educação tecnocientífica crítica.

$M$ uito se tem falado em promover um ensino crítico (independentemente do nível de escolaridade), mas pouco se tem discutido sobre o sentido desse ensino e dessa crítica. 0 que é necessário para promover um ensino crítico? 0 que é um ensino crítico? 0 que isso tem a ver com ciência e com tecnologia?

$\mathrm{N}$ ão pretendemos ter respostas para tais questões, nem responder definitivamente alguma delas ao longo de nossa análise. Indicamos alguns caminhos possíveis. Por meio das falas analisadas, falas de profissionais/estudantes envolvidos com processos educativos, foi possível evidenciarmos a presença de alguns elementos que direcionam o olhar para um processo de formação que busque a reflexão, a não passividade.

Entre tantas questões, evidenciamos as concepções de leitura como influência importante nessa busca de formação e atuação profissional que considere o sujeito como leitor de mundo e produtor de sentidos. A abordagem de questões oriundas dos ECTS a partir dessa perspectiva torna-se um caminho muito adequado, na medida em que contribui para que outras leituras sejam realizadas e debatidas como algumas das possíveis e não as únicas viáveis. Considerar a ciência e a tecnologia numa abordagem discursiva permite abrir espaço para que sejam percebidas como construções culturais, localizadas histórica e socialmente.

Para chegarmos à outra margem no processo formativo universitário, de forma que ele não se limite ao aprimoramento contínuo e exclusivo de conhecimentos tecnocientíficos descontextualizados, mas que torne possível percorrer outros caminhos, perceber outros cenários e os mesmos cenários com outros ol hares, acreditamos ser bastante adequado favorecer uma abordagem mais polissêmica sobre linguagem e relações CTS, que estão ali a compor o conjunto das pedras que nos orientam na travessia do rio.

\section{Referências bibliográficas}

ALM EID A, M .J. P. M . D iscursosda ciência eda escola: ideologiaseleituras possíveis. C ampinas: M ercado de Letras, 2004.

AT KIN SO N , D . Scientific discoursein sociohistorical context. Philosophical transactions of the Royal Society of London, 1675-1975. M ahwah, N ew Jersey: LawrenceErlbaum Associates, Publishers, 1999.

AUTHIER-REVUZ, J. et al. Palavrasincertas asnão-coincidências do dizer. Campinas: Ed. daU NICAM P, 1998. 
CASSIAN I DE SO UZA, S. C.; ALM EID A, M .J. P. M . Leiturasnamediação escolar em aulas deC iências: afotosśnteseem textos originais decientistas. Pro-Pos ções- FE/U nicamp, v. 12, n. 1 (34), p. 110-125, 2001.

CASSIAN I DE SO UZA, S. C.; N ASCIM EN TO, T. G .U m diálogo com ashistórias deleituras defuturos professores deciências. Pro-Posições- FE/U nicamp, v. 17, p. 105-136, 2006.

DAGN IN O, R. N eutralidade da ciência e determinismo tecnológico: um debate sobre a tecnociência. Campinas, SP: Editora da U nicamp, 2008.

FLOR, C.; CASSIAN I DE SO UZA, S. C ondições de produção deleituras de estudantes em aulas de química no ensino médio. In: CONGRESO INTERN ACIONAL SOBRE IN VESTIGACION EM DID ACTICA DE LAS CIEN CIAS, 7., 2009, Barcelona. Atas..

FREIRE, A. M . A. Paulo Freire: uma história de vida. Indaiatuba: Villa das Letras, 2006.

LIN SIN GEN , I. von. A educação tecnológicanuma perspectivaCT S: convergênciascurriculares. Revista deEnsino deEngenharia - ABEN GE, Brasília, v. 22, n. 2, p. 21-30, 2003.

LIN SIN GEN , I. von. Perspectiva educacional CTS: aspectos de um campo em consolidação naAméricaLatina. Ciência \& Ensino - U nicamp, C ampinas, v. 1, p. 1-16, 2007. D isponível em: 〈http://www.ige.unicamp.br/ojs/index.php/cienciaeensino/article/view/150/108>. Acesso em: março de 2010.

LIN SIN GEN , I. von; CASSIAN I de SO UZA; PEREIRA, P. Repensando a formação de professores de ciências numa perspectiva CT S: al gumas intervenções. In: CO N G RESSO ARGENTINO DE EST UDOSSO CIAISD A CIÊN CIA E DATECN OLOGIA, 1., 2007, BuenosAires.

M ARQ U ES, L. R. D emocraciaradical edemocraciaparticipativa: contribuiç̧õesteóricasà análise dademocracianaeducação. Educação eSociedade, Campinas, SP, v. 29, n. 102, p. 55-78, jan./abr., 2008. D isponível em: 〈tttp://www.cedes.unicamp.br>. Acesso em: junho de2009.

N ASCIM ENTO ,T. G .; VON LIN SIN GEN , I. Articulaçõesentre o enfoqueCTS eapedagogia dePaulo Freirecomo basepara o Ensino deCiências. In: Revista Convergencia, Toluca, v. 13, p. 95-116, 2006.

O RLAN DI, E. P. A linguagem eseu funcionamento. Campinas: Pontes, 1996.

O RLAN DI, E. P. Colonização, globalização, tradução e autoria científica. In: GUIM ARÃES, E. (O rg.). Produção e circulação do conhecimento. Política, ciência, di vulgação. C ampinas, SP: Pontes, 2003. v. 2.

SILVA, H . C.; BAEN A, C. R.; BAEN A, J. R. 0 dado empírico delinguagem na perspectivada análise de discurso francesa: um exemplo sobre as relações discursivas entreciência, cotidiano e leitura. Ciência eE ducação - U N ESP, Bauru, v. 12, p. 347-364, 2006.

SO UZA, O .; BO H N , H . Escrita ecidadania. Florianópolis: Insular, 2003.

SUTT O N , C. Los professores de ciencias como professores de lenguaje. Enseñanza de las Ciências, v. 21, n. 1. p. 21-25, 2003.

Recebido em 15 deoutubro de2010 eaprovado em 10 dedezembro de 2010.

Pro-Posições, Campinas, v. 22, n. 1 (64), p. 59-70, jan./abr. 2011 